\title{
Numerical Simulation Study of Pore-Throat Evolution of Upper Paleozoic in Ordos Basin, China
}

\author{
Qing Cao $\mathbb{D}^{1},{ }^{1}$ Zhangxing Chen, ${ }^{2}$ JingZhou Zhao, ${ }^{1}$ Jiacheng Dang, ${ }^{1}$ Jiaxuan Song $\mathbb{D},{ }^{3}$ \\ and Bin Chen ${ }^{1}$ \\ ${ }^{1}$ Shaanxi Key Laboratory of Petroleum Accumulation Geology, Xi'an Shiyou University, Shaanxi 710065, China \\ ${ }^{2}$ Reservoir Simulation Group, Department of Chemical \& Petroleum Engineering, University of Calgary, Alberta, Canada T2N 1N4 \\ ${ }^{3}$ Research Institute of Yanchang Petroleum (Group) Co., Ltd., Xi'an, 710065 Shaanxi, China \\ Correspondence should be addressed to Qing Cao; caoqing@xsyu.edu.cn
}

Received 22 January 2021; Accepted 9 May 2021; Published 4 June 2021

Academic Editor: Richeng Liu

Copyright ( 2021 Qing Cao et al. This is an open access article distributed under the Creative Commons Attribution License, which permits unrestricted use, distribution, and reproduction in any medium, provided the original work is properly cited.

\begin{abstract}
The parameters of grain size, contents of silica, kaolinite, hydromica, calcite, and a geological time of tight sandstone reservoirs in Upper Paleozoic in Ordos basin were researched thoroughly, and the impact of the diagenetic evolution process of different sandstone types on porosity and throats was analyzed, based on the quantitative statistics from thin sections, measurements of porosity and permeability, and conventional and constant-rate mercury injection tests. We not only build the evolution of porosity through process-oriented numerical simulations during the geological time but also establish effect-oriented numerical simulations between porosity and different diagenesis parameters. Furthermore, we set up a fitting relationship between diagenetic factors and pore throats in different gas-bearing reservoirs. Differentiation results in the evolution of porosity and a pore-throat system of sandstone types have clear characteristics, such as lithic quartz sandstones of the He 8 Member in the Sulige area and quartz sandstones of the Shan 2 Member in the Yulin area. The fitting results show that the main factors influencing the evolution of porosity and a pore-throat system are grain size and siliceous cement, which can also be validated by the measured data on two gas-bearing intervals. The results are important to a deep understanding of the relationship between the reservoir continuing to experience porosity and permeability evolution and the timing of petroleum charging into the reservoir and can also be applied elsewhere as a quick means in high grading areas of risks during field development.
\end{abstract}

\section{Introduction}

Recovery of porosity evolution in a sandstone diagenetic process based on the analysis of reservoir diagenesis has been a research focus all the time. Scientifically and accurately recovering a pore compact process is particularly important to analyze the accumulation and compactness successive coupling relationship of a tight sandstone reservoir. Numerous related tests and simulations have been conducted to recover the porosity evolution. Earlier studies suggested that there is a certain fitting relationship between porosity and some factors like depth, effective stress, lithology, lithofacies, and temperature as well as time [1-8]. The analysis of the controlling factors of the microscopic pore structure of tight sandstone reservoirs is not only controlled by the distribution of diagenetic products but also by the original sedimentary characteristics of sandstone (debris particle composition and structure), as well as the water-rock interaction in the reservoir [9-15]. They provide a more scientific basis for the further explanation of densification causes of sandstone reservoirs.

Geological numerical simulations are generally divided into two categories: process-oriented and effect-oriented. The process-oriented is mainly aimed at single diagenesis parameters, and the effect-oriented considers superposed results correspondingly, both processes were affected by a comprehensive influence of various diagenetic factors [16-20]. The fitting analysis in this study was based on diverse laboratory test results and a large number of thin section identification results. Additionally, effect-oriented numerical simulations are established from the macroscopic porosity and microscopic pore-throat radius views, 
respectively, and an estimation formula of porosity and pore throats has been proposed. Comparing the simulated data to the measured data and showing the practical value of these models with examples, numerical simulations thus provide a scientific basis for the analysis of the densification process in tight sandstones of Upper Paleozoic in Ordos Basin.

\section{Background and Diagenesis Sequences}

The Upper Paleozoic tight gas reservoirs in the Ordos Basin covered a large area and have many gas-bearing formations and multiple pressure systems. The tight reservoirs, which were formed before gas accumulation, are of high heterogeneity. Almost all gas-bearing reservoirs of the Ordos basin show the same characteristics, which are low porosity, low permeability, low reserve abundance, and a large area distribution [21, 22]. Meanwhile, the gas-bearing strata are numerous, and their spatial distribution is complicated. The largest two tight sandstone gas fields are Sulige and Yulin, which have been discovered in the Yishan slope and also are the main research areas (Figure 1). The results of research on the gas accumulation in this area suggested that the type of the reservoir is close to a "quasi-continuous gas reservoir" $[23,24]$.

The exploration results suggested that the main gasbearing intervals in the Upper Paleozoic are quartz sandstone, lithic quartz sandstone of the He 8 Member in the Shihezi Formation in the Sulige area, and quartz sandstone of the Shan 2 Member in the Shanxi Formation in the Yulin area. The average porosity values of these gas-bearing sand bodies are $8.6 \%$ and $6.2 \%$, and the average permeability values are $0.74 \times 10^{-3} \mu \mathrm{m}^{2}$ and $4.48 \times 10^{-3} \mu \mathrm{m}^{2}$, respectively. Fitting the median pore-throat radius of the main gasbearing interval Upper Paleozoic which was obtained from conventional mercury injection tests, and the mean value of a pore radius and a throat radius which were obtained from constant-rate mercury injection tests with the permeability of cores, there is no significant correlation between the mean pore radius, the mean throat radius, and permeability (Figure 2). However, a correlation between the median radius of pore throats and permeability is obvious [25].

By analyzing the laboratory data on conventional thin sections, cast thin sections, SEM, and cathode luminescence, it is shown that the diagenesis evolution of the gas-bearing reservoirs in the Ordos Basin is complicated and mainly dominated by compaction, cementation, and dissolution. Various diagenetic phenomena combined with the petrographic characteristics and their homogenization temperatures of fluid inclusions indicate that the main gas-bearing reservoirs have experienced complicated multistage diagenesis and a long term of the natural gas charging process. The diagenetic sequences of the gas-bearing sandstone reservoirs were as follows: Chlorite film $\rightarrow$ compaction $\rightarrow$ natural gas began to charge $\rightarrow$ quartz overgrowth $\mathrm{I} \rightarrow$ dissolution $\mathrm{I} \rightarrow$ natural gas continuous charging $\rightarrow$ quartz overgrowth II $\rightarrow$ kaolinite $\rightarrow$ illite $\rightarrow$ large amount of natural gas charging $\rightarrow$ calcite $\rightarrow$ dissolution II $\rightarrow$ structural fractures [26-29].

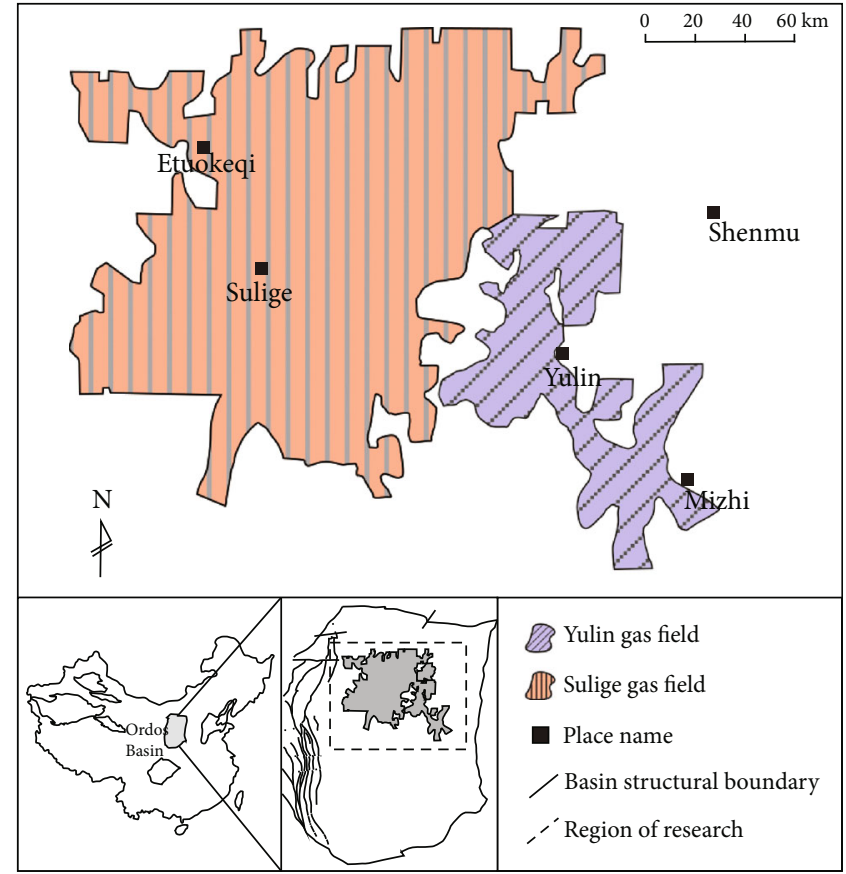

Figure 1: Location map of the research area in the Ordos Basin.

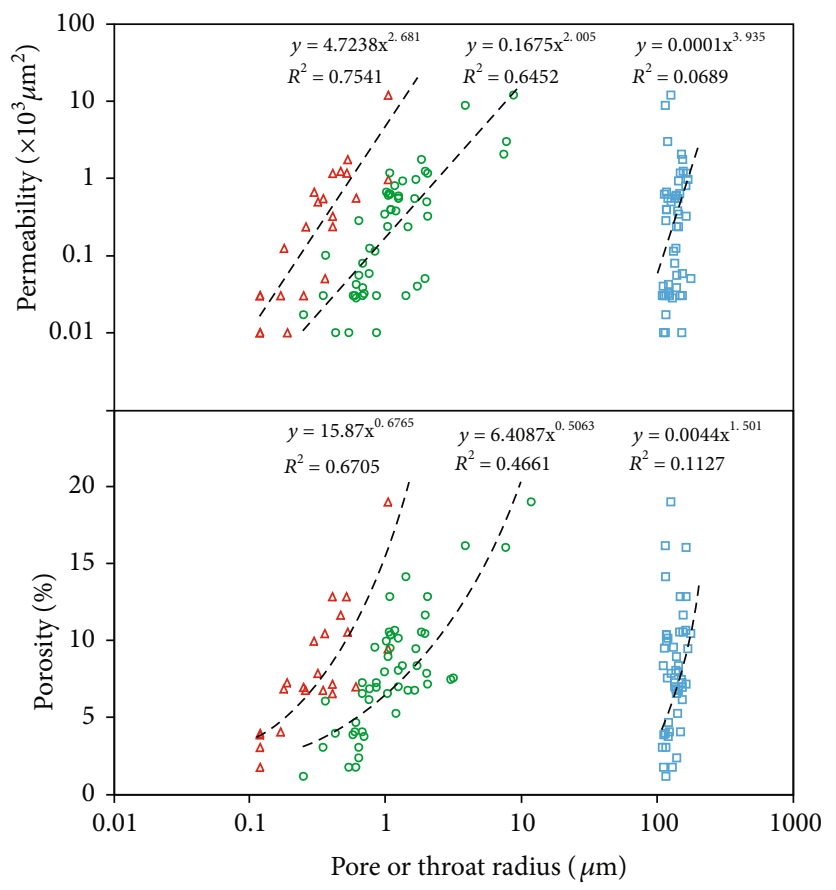

\footnotetext{
Median radius

$\triangle$ of pore-throat

O Mean throat radius

$\square$ Mean pore radius
}

FIgURE 2: Relationship of average radius in pores, throats, and median pore-throats in the Upper Paleozoic in the Ordos Basin. 


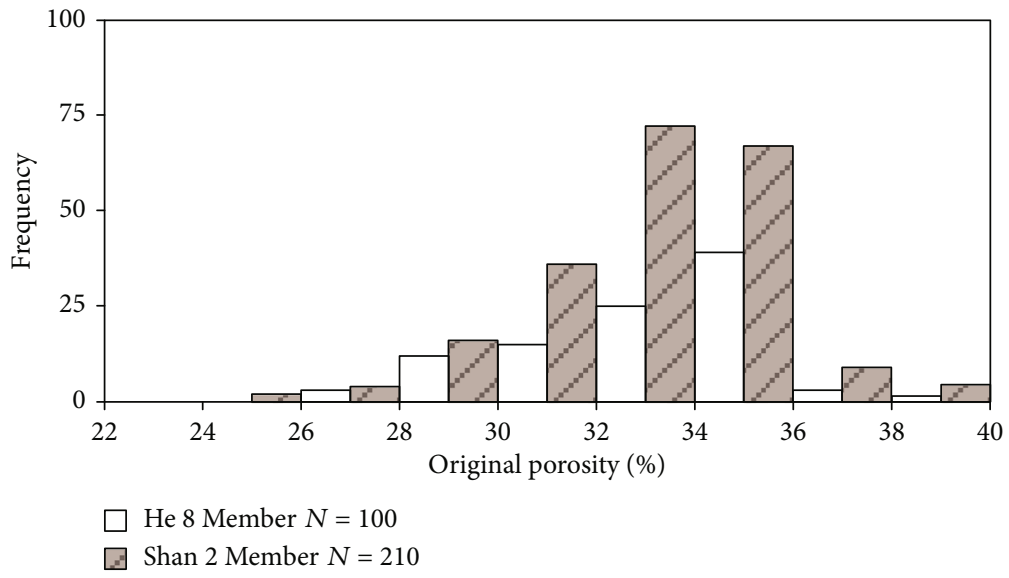

Figure 3: The distribution of original porosity in the Upper Paleozoic in the Ordos Basin.

\section{Numerical Simulation of Sandstone Porosity Evolution}

The evolution of tight sandstone reservoirs was constrained by both sedimentation and diagenesis. The pore-throat condition of current tight sandstone reservoirs is the result of multiple diagenetic modifications on the basis of primary pore-throat characteristics. A fitting relationship between the varying number of pore throats and the diagenesis parameters during different diagenetic stages should be quantitatively analyzed first in order to reasonably simulate the evolution of pores and throats.

3.1. Establishment of a Fitting Relationship between Diagenesis and Porosity. The original porosity of sandstones is usually calculated by using the original porosity relation [3] under different sorting coefficients: original porosity = $20.91+22.90$ /sorting coefficient. Different layers of sorting coefficients and the estimated original porosity result (Figure 3) show that the original porosity of the main gasbearing intervals in the Upper Paleozoic ranges from $24 \%$ to $36 \%$, among which the original porosity of the Shan 2 Member in the Yulin area is $34.5 \%$, while that of the He 8 Member in the Sulige area is $33.9 \%$.

A lot of the previous studies which aimed at the porosity reduction strength of compaction and cementation of the Upper Paleozoic reservoirs in the Ordos basin were done. The statistical results showed that the strength of the compactional porosity loss is mostly between $50 \%$ and $75 \%$, which is obviously larger than the strength of the cementation decrease porosity $[18,21,26,30-32]$. Based on the porosity loss calculation formula [33] and the observation of casting thin sections, the cross plot of a compactioncementation porosity reduction rate for different rock types was drawn (Table 1). The statistical results show that the compaction porosity reduction rate of quartz sandstone in the Shan 2 Member in the Yulin area is relatively low, ranging from $35 \%$ to $70 \%$ with an average of $55 \%$. The lithic quartz sandstone compaction porosity reduction rate of the $\mathrm{He} 8$ Member of the Sulige area is varying from $50 \%$ to $80 \%$ with an average of $63 \%$.
According to the comparison of the tight sandstone cement, it can be seen that the total amounts of sandstone cement are similar basically in the main gas-bearing intervals of different areas (Table 2). However, silicone cement is the main component of the Shan 2 Member in the Yulin area while the He 8 Member in the Sulige area is dominated by clay minerals (kaolinite and hydromica).

The comparison of the pore types of the main gasbearing interval sandstones shows that the lithic quartz sandstone of the He 8 Member in the Sulige area had the highest surface porosity with a value of $3.99 \%$, which is mainly composed of lithic dissolution pores and the residual intergranular pores, accounting for $33 \%$ and $28 \%$, respectively (Table 3). Its dissolution porosity increase rate is over $70 \%$. The quartz sandstone of the He 8 Member in the Sulige area has similar pore characteristics to lithic quartz sandstone, with a relatively low porosity of about $60 \%$. The quartz sandstone of the Shan 2 Member in the Yulin area owns the second-highest surface porosity with approximately 55\% residual intergranular pores; moreover, the intergranular and intercrystalline pores account for about $20 \%$, respectively, while the dissolution porosity increase rate is less than $40 \%$.

3.2. Process-Oriented Simulation of Sandstone Porosity Evolution. The evolution of diagenesis of tight reservoirs during the geological time-three-dimensional space process is a comprehensive superposition effect of various diagenetic factors. The porosity evolution process is divided into a pore reduction affected by compaction, a pore reduction affected by cementation, and a pore formation affected by dissolution. The diagenetic evolution shows significant differences between lithic quartz sandstone in the He 8 Member and quartz sandstone in the Shan 2 Member (Table 4).

For the quartz sandstone and lithic quartz sandstone in the He 8 Member in the Sulige area, the grain size of the sandstone is relatively coarse, and the original porosity generally varies from $24 \%$ to $36 \%$, with an average of $33 \%$. Prediagenetic compaction results in a loss of the primary porosity of about $63 \%$. The primary intergranular pores after compaction are around $12.2 \%$, and about $15 \%$ porosity was obtained from dissolution. Kaolinite clay mineral cement is 
TABLE 1: The cross plot of compaction and cementation porosity reduction rate in main gas-bearing intervals.

\begin{tabular}{lcc}
\hline & He 8 Member in Sulige area $(N=280)$ & Shan 2 Member in Yulin area $(N=420)$ \\
\hline The compaction porosity reduction rate & $62 \pm 1 \%(50 \%-80 \%)$ & $55 \pm 1 \%(35 \%-70 \%)$ \\
The cementation porosity reduction rate & $33 \pm 1 \%(20-40 \%)$ & $35 \pm 1 \%(20-50 \%)$ \\
\hline
\end{tabular}

TABLe 2: Different cement in quartz sandstone and lithic quartz sandstone.

\begin{tabular}{|c|c|c|c|c|c|c|c|}
\hline Area/formation & Lithology & Sample number & Total amount & Silica & Kaolinite & Hydromica & Calcite \\
\hline \multirow{2}{*}{ He 8 Member in Sulige area } & Quartz sandstone & 780 & 13.6 & 4.7 & 3.4 & 2.8 & 2.7 \\
\hline & Lithic quartz sandstone & 2010 & 12.5 & 2.4 & 2.1 & 5.9 & 2.1 \\
\hline \multirow{2}{*}{ Shan 2 Member in Yulin area } & Quartz sandstone & 376 & 13.6 & 6.9 & 3.0 & 1.5 & 2.2 \\
\hline & Lithic quartz sandstone & 212 & 13.5 & 6.1 & 3.5 & 1.7 & 2.2 \\
\hline
\end{tabular}

TABLE 3: Different pore types in quartz sandstone and lithic quartz sandstone.

\begin{tabular}{|c|c|c|c|c|c|c|c|}
\hline Area/formation & $\begin{array}{l}\text { Sample } \\
\text { number }\end{array}$ & Lithology & $\begin{array}{l}\text { Surface } \\
\text { porosity }\end{array}$ & $\begin{array}{c}\text { Residual } \\
\text { intergranular }\end{array}$ & $\begin{array}{l}\text { Dissolution } \\
\text { intergranular }\end{array}$ & $\begin{array}{c}\text { Lithic } \\
\text { dissolution }\end{array}$ & Intercrystalline \\
\hline \multirow{2}{*}{$\begin{array}{l}\text { He } 8 \text { Member in } \\
\text { Sulige area }\end{array}$} & 450 & $\begin{array}{l}\text { Quartzose } \\
\text { sandstone }\end{array}$ & 3.85 & 1.53 & 0.67 & 1.07 & 0.58 \\
\hline & 710 & $\begin{array}{l}\text { Lithic quartzose } \\
\text { sandstone }\end{array}$ & 3.99 & 1.12 & 0.99 & 1.33 & 0.55 \\
\hline \multirow{2}{*}{$\begin{array}{l}\text { Shan } 2 \text { Member in } \\
\text { Yulin area }\end{array}$} & 376 & $\begin{array}{l}\text { Quartzose } \\
\text { sandstone }\end{array}$ & 3.65 & 2.02 & 0.66 & 0.25 & 0.72 \\
\hline & 212 & $\begin{array}{l}\text { Lithic quartzose } \\
\text { sandstone }\end{array}$ & 2.68 & 1.11 & 0.56 & 0.48 & 0.53 \\
\hline
\end{tabular}

TABLE 4: Porosity evolution of different diagenetic stage (average/data range).

\begin{tabular}{|c|c|c|c|}
\hline Diagenetic stage & Type of diagenesis & $\begin{array}{l}\text { He } 8 \text { Member in Sulige area } \\
\text { Quartz sandstone and lithic quartz sandstone }\end{array}$ & $\begin{array}{c}\text { Shan } 2 \text { Member in Yulin area } \\
\text { Quartz sandstone }\end{array}$ \\
\hline \multicolumn{2}{|c|}{ Original porosity (\%) } & $33 / 24-36$ & $34 / 28-38$ \\
\hline \multirow{2}{*}{ Early diagenesis } & Compaction & Decrease $62 \%$ & Decrease $55 \%$ \\
\hline & Cementation & Decrease $1 \%$ & Decrease $1 \%$ \\
\hline \multicolumn{2}{|c|}{ Porosity at the end of Triassic (\%) } & $12.2 / 8.9-12.6$ & $14.9 / 12.3-16.7$ \\
\hline \multirow{4}{*}{ A stage of late diagenesis } & Siliceous cement $(I)$ & Decrease $5 \%$ & Decrease $10 \%$ \\
\hline & Dissolution & Increase $15 \%$ & Increase $6 \%$ \\
\hline & Siliceous cement $(I I)$ & $0 \%$ & Decrease $4 \%$ \\
\hline & Clay cement & Decrease $18 \%$ & Decrease $12 \%$ \\
\hline \multicolumn{2}{|c|}{ Porosity in early cretaceous (\%) } & $9.2 / 6.7-10.8$ & 8.2/6.7-9.1 \\
\hline \multirow{2}{*}{ B stage of late diagenesis } & Carbonate cement & Decrease $5 \%$ & Decrease 3\% \\
\hline & Carbonate dissolution & Increase $1 \%$ & Increase $1 \%$ \\
\hline \multicolumn{2}{|c|}{ Porosity in present $(\%)$} & $8.3 / 5.9-9.1$ & $7.5 / 6.2-8.4$ \\
\hline
\end{tabular}

relatively more while siliceous cement is relatively less. The porosity of the sandstone is additionally reduced after cementation, resulting in a final residual porosity of about $5.9 \%$ to $9.1 \%$.

For the quartz sandstone of the Shan 2 Member in the Yulin area, with relatively coarse grain and better sorting, the original porosity ranges from $28 \%$ to $38 \%$ with an average of $34 \%$. The fairly high quartz content in sandstone provided a relatively strong compressive capacity of compaction so that a reduction in the primary porosity of sandstone is comparatively slow. The original porosity lost about 56\% after compaction and early cementation. Kaolinite cement is a relatively less cementitious material but siliceous cement is relatively more. After cementation, the porosity of the sandstone is further reduced, making a final residual porosity of about $6.2 \%-8.4 \%$.

3.3. Effect-Oriented Simulation of Porosity Evolution. There is a power relation among independent variables when the correlation between dependent variables and independent variables is explained by the regression model in the practical data simulation process. In order to improve the accuracy 


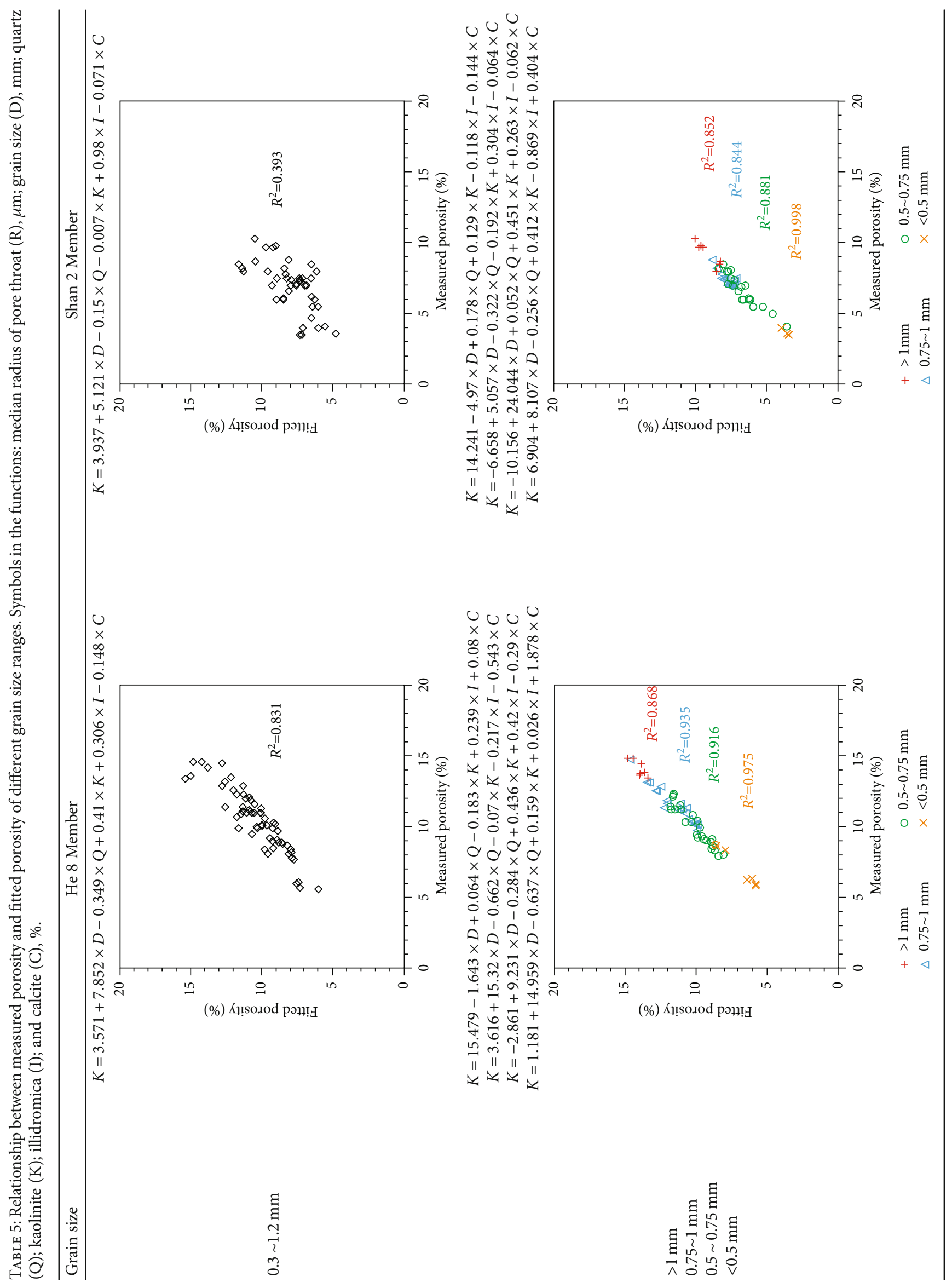



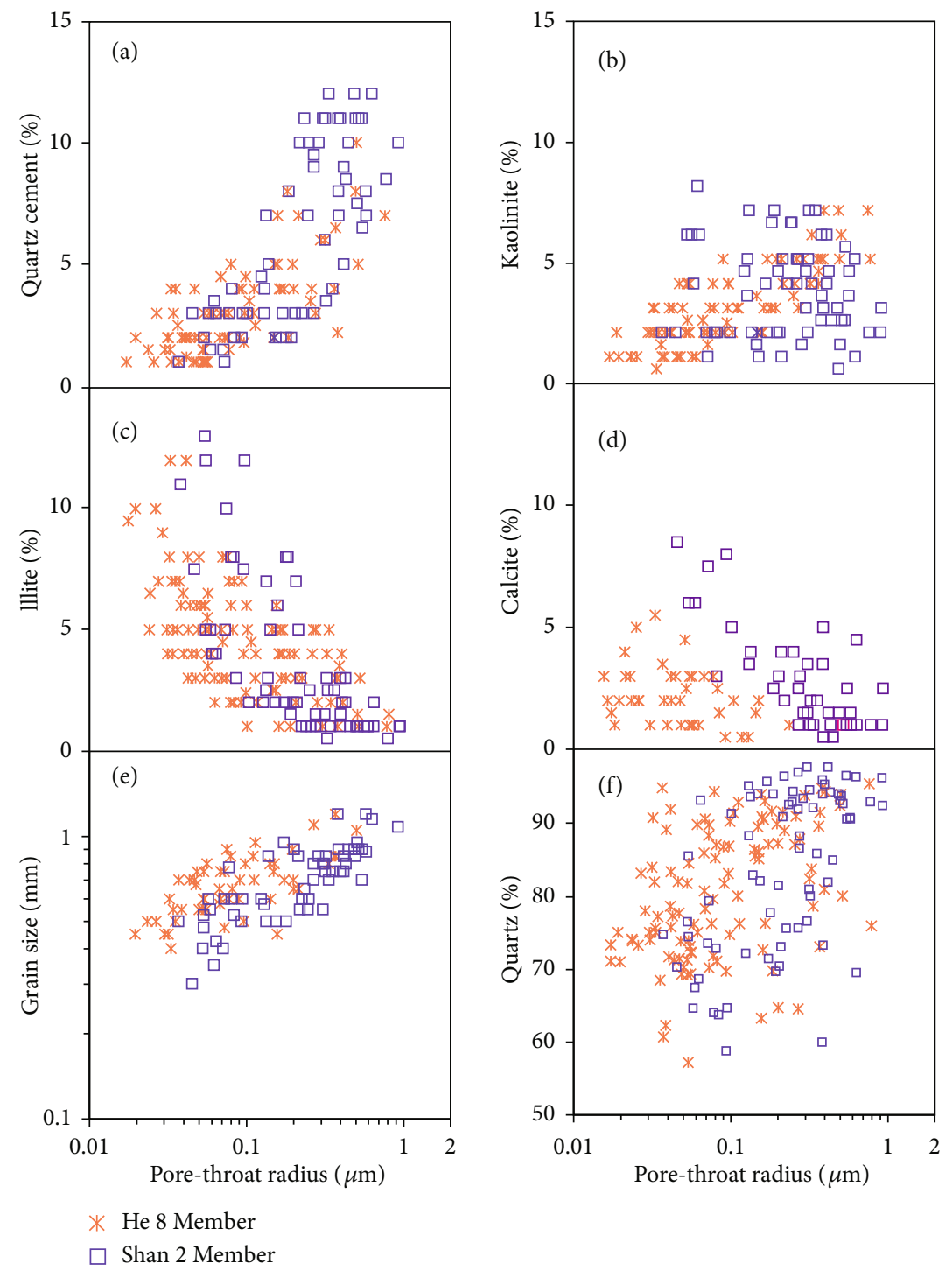

FIGURE 4: Relationship between pore-throat radius and major cementation parameters.

and reliability of polynomial regression prediction, principal component analysis (PCA) can carry out dimensionality reduction of different types of data, which maps the original set of independent variables from a high-dimensional space to a low-dimensional space through a linear transformation. Based on the premise of the lowest loss of original data information, the principal component analysis (PCA) extracts the largest amount of information about the original variables in the low-dimensional space and generates new comprehensive variables accordingly. Therefore, the results of regression analysis are not affected by the analysis method as much as possible [34, 35].

A principal component analysis algorithm was used to establish an effect-oriented function between porosity and diagenetic factors, based on the parameters of grain size and contents of silica, kaolinite, hydromica, and calcite $[36,37]$. The principal component regression analysis is established by porosity and multiple diagenetic parameters without considering the grain size, which results show that the correlation coefficients of the He 8 Member are higher than 0.83 , but correlation coefficients of the Shan 2 Member are lower than 0.40 correspondingly (Table 5-a, b). The results of multifactor numerical effect-oriented simulations and measured porosity data show an obvious deviation regardless of the difference in the grain size. The effectoriented simulations of porosity and the major diagenetic factors should be established segmentally with different grain size ranges $(0<0.5 \mathrm{~mm}, 0.5-0.75 \mathrm{~mm}, 0.75-1 \mathrm{~mm}$, and $>1 \mathrm{~mm}$ ), which correlation coefficients of the $\mathrm{He} 8$ Member and the Shan 2 Member are both higher than 0.84 (Table 5-c, d). A quadratic sum of errors between the fitted and measured data is less than 0.1, indicating that the porosity fitting result is fairly reliable. The fitting results show that the main factors affecting the evolution of a porethroat system are grain size and the content of the siliceous cement (Table 5). 


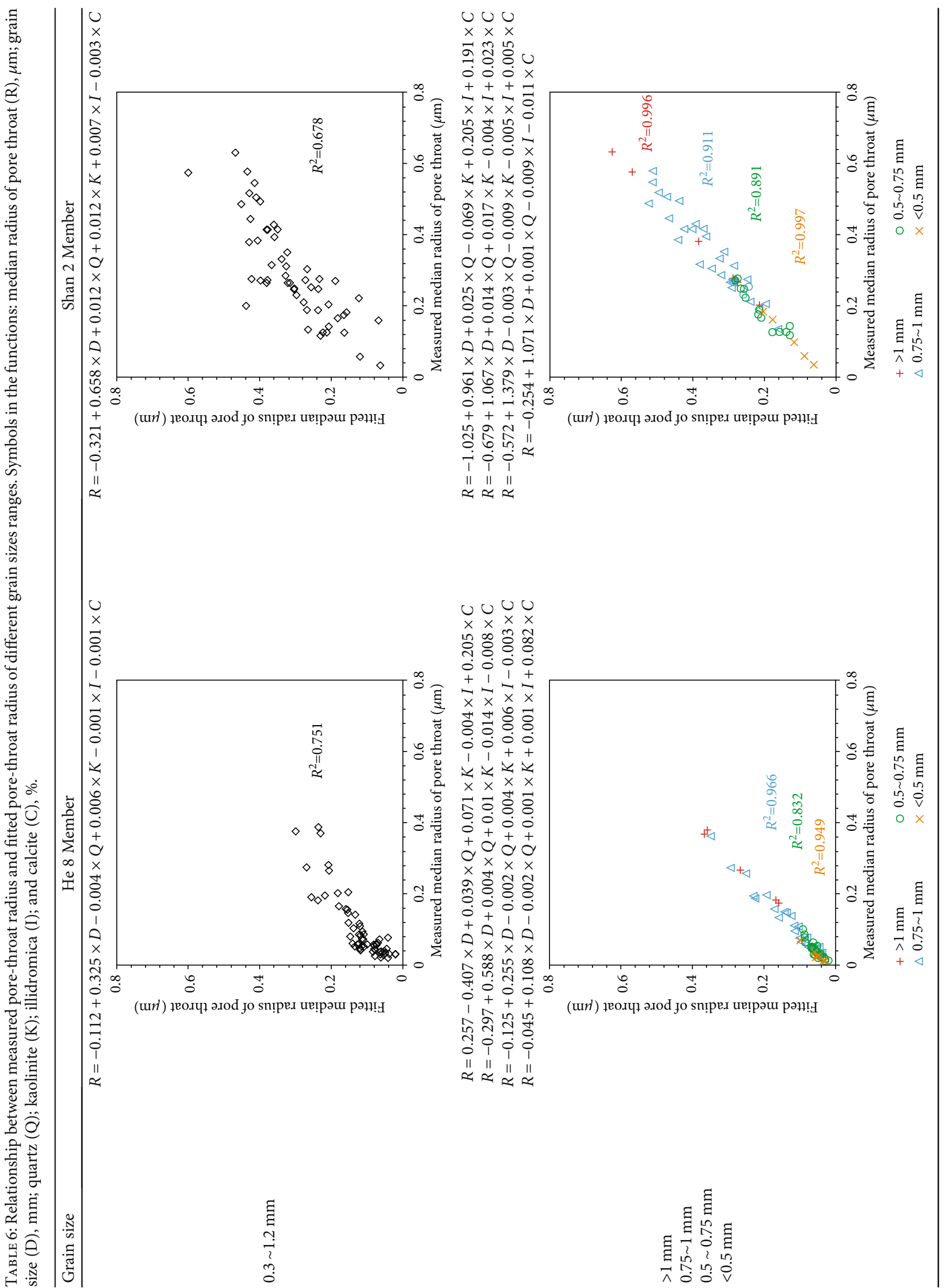




\section{Numerical Simulation of Sandstone Throat Evolution}

4.1. Fitting Relationship between Diagenetic Factors and Median Throat Radius. A pore-throat radius is affected by various diagenetic factors during a geological time-threedimensional space process. Besides, the pore-throat radius is a segmented function with a change in the diagenesis stage. It is the first attempt to establish a fitting relationship between a single diagenetic factor and a pore-throat radius from the microperspective of a pore-throat system and establish numerical simulations for the median radius on this basis.

According to the test results of rock composition, grain size, and properties, it was found that there is no obvious correlation between the quartz content and the physical properties when the sorting and the rounding degree are roughly similar, but a positive correlation between the grain size and the median pore throat radius is obvious (Figure 4(a)). Based on the analysis of the rock grain size and property test results, it is shown that the contents of siliceous, kaolinite, hydromica, and calcite are negatively correlated with porosity; that is, as the cement content increases, the porosity decreases accompanied by a declining reservoir storage coefficient. Hydromica and calcite cement contents are negatively correlated with the pore throat median radius (Figure 4(b)); i.e., with the contents of hydromica and calcite cement increased, the median pore-throat radius decreases, and thus is not conducive to natural gas accumulation. However, the content of siliceous and kaolinite cement is positively correlated (Figure 4(c)) with the pore throat median radius.

With an increase in siliceous and kaolinite cement, the throats of sandstone reservoirs are preserved and further transformed. Therefore, silica and cement reduce the energy storage coefficient of sandstone reservoirs, but they help to preserve the throats between the pores connecting the sandstone reservoirs and facilitate the filling and accumulation of natural gas. There is no obvious correlation between lithic dissolution porosity, intergranular pores, and the median pore-throat radius, which indicates that these pores contribute little to sandstone throats; in other words, these pores have less contribution to improving reservoir seepage ability.

4.2. Effect-Oriented Simulation of Pore-Throat Radius. The principal component analysis (PCA) algorithm was used to establish a segmented effect function of the pore-throat radius. The pore-throat system evolution process was divided into three aspects: compaction reducing pore throats, cementation maintaining pore throats, and cementation reducing pore throats. The effect simulation between the pore median throat radius and diagenetic factors on different diagenetic stages is established according to the particle size and the contents of siliceous, kaolinite, hydrous mica, and calcite.

Without considering the difference in grain size, the multivariate numerical effect-oriented simulation results show an obvious deviation where the pore throat radius is relatively large. Those correlation coefficients of the He 8 Member and Shan 2 Member are lower than 0.75 (Table 6-a, b). Therefore, the particle size and contents of siliceous, kaolinite, hydrous mica, and calcite were taken as the main calculation factors for different grain sizes, and the segmented effect function of the median pore-throat radius and diagenetic factors was further established in different grain size ranges $(0<0.5 \mathrm{~mm}, 0.5-0.75 \mathrm{~mm}, 0.75-1 \mathrm{~mm}$, and $>1 \mathrm{~mm})$. Therefore, those principal component regression analyses have been reestablished in different particle size intervals, in which correlation coefficients of the $\mathrm{He}$ 8 Member and the Shan 2 Member are both higher than 0.83 (Table 6-c, d). The simulation results show that the main influencing factors also are grain size and the content of siliceous cement.

4.3. Fitting Results Comparison. The simulation models were applied to five well locations throughout the field, ranging from lithic quartz sandstone of the He 8 Member and quartz sandstone of the Shan 2 Member in different areas. The accuracy of the porosity and pore-throat radius fitting results is validated by the measured data in two gas-bearing intervals. The simulation model can analyze the relationship between the reservoir continuing to experience porosity and permeability evolution and the timing of petroleum charging to the reservoir and can also be applied elsewhere as a quick means of high grading areas of risks during field development (Figures 5(a) and 5(b)). The corresponding porosity and pore throat radii are calculated according to the thin section data and the fitting formula. A quadratic sum of errors between the fitted and measured data is less than 0.1 , indicating that the porosity fitting result is fairly reliable (Figures 5(c) and 5(d)).

According to the results of the porosity segmented simulation and effect-oriented simulation, the evolutionary history of the pores of the tight sandstone in the Upper Paleozoic in the Ordos Basin can be summarized as follows: the porosity of the He 8 Member in the Sulige area is less than $12 \%$ at the end of the early-diagenesis period (Late Triassic), partly densified. The porosity is less than $11 \%$ at the end of the middle diagenesis stage A (Early Cretaceous), mostly densified. The present porosity is less than $9 \%$, mostly densified. The porosity of the Shan 2 Member in the Yunlin area is less than $15 \%$ at the end of the late diagenesis stage, partly densified. The porosity from the middle diagenesis stage A to the present is less than $9 \%$, mostly densified. Based on the segmented simulation of a pore-throat radius and the results of effect-oriented simulation, the evolution history of the tight sandstone throat in the Upper Paleozoic in the Ordos Basin is as follows: the median pore-throat radius of the He- 8 in the Sulige area at the end of the early diagenesis period is less than $0.13 \mu \mathrm{m}$ (Late Triassic), mostly densified. The median pore-throat radius in the middle diagenesis stage A to the present is less than $0.1 \mu \mathrm{m}$ (Early Cretaceous to present), entirely densified. The major median pore-throat radius of the Shan 2 Member in the Yulin area in the early diagenesis stage is between $0.07 \mu \mathrm{m}$ to $0.58 \mu \mathrm{m}$ (Late Triassic), partly densified. The pore throat radius in the middle diagenesis stage A to the present is between $0.11 \mu \mathrm{m}$ to $0.47 \mu \mathrm{m}$ (Early Cretaceous to present), partly densified. 


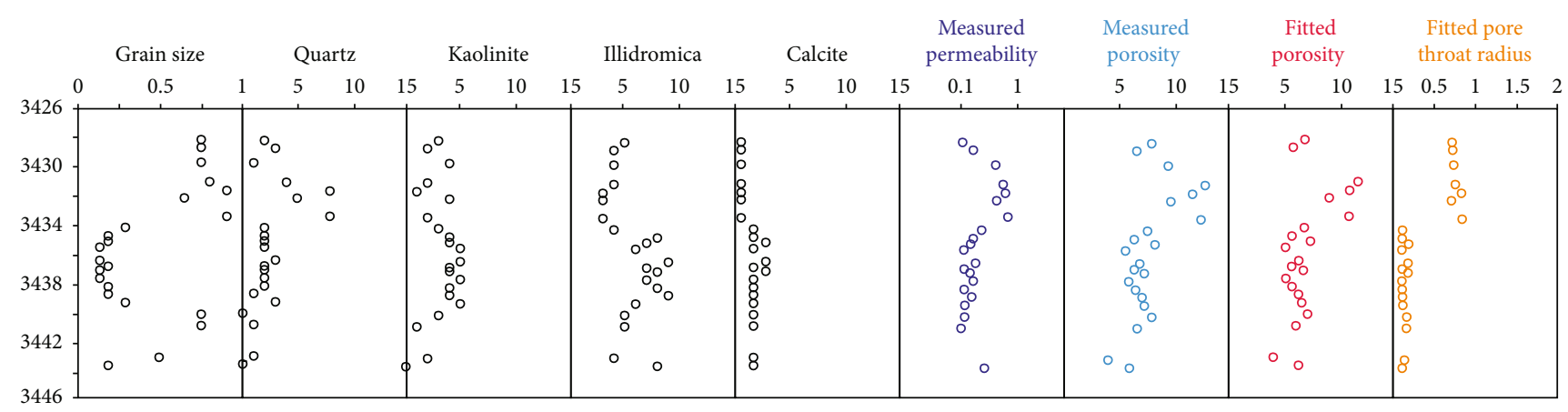

(a)

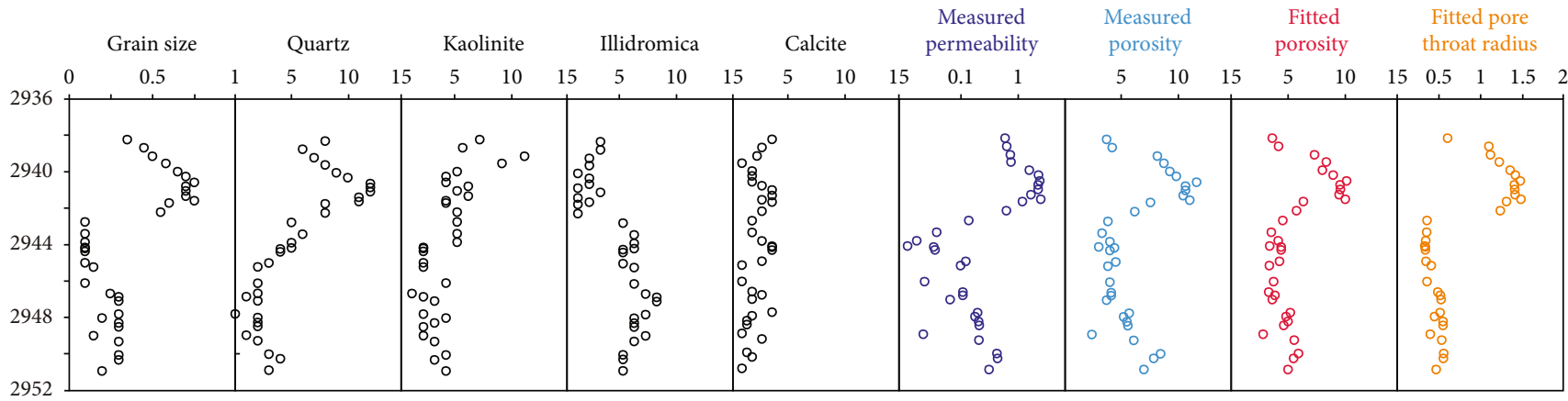

(b)

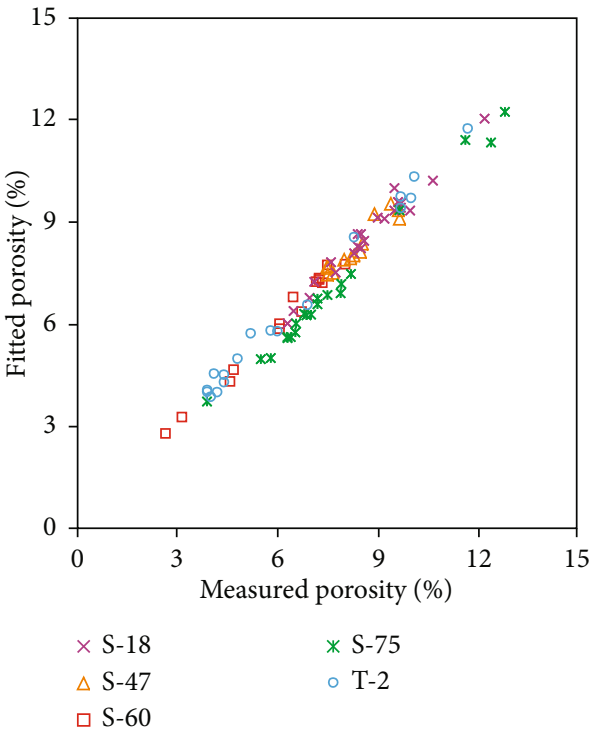

(c)

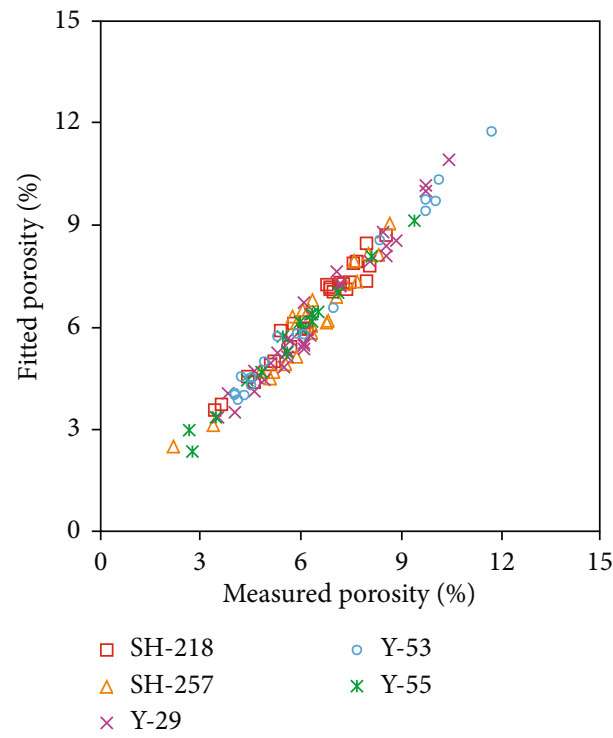

(d)

FIGURE 5: The accuracy of the porosity and pore-throat radius fitting results and measured data of 10 well in different areas ((a) Su-75 well, He 8 Member; (b) Shan-218 well, Shan 2 Member; (c) data about the He 8 Member, Su- 60 well, Su-47 well, Su-18 well, Su-75 well, Tao-2 well; (d) data about the Shan 2 Member, Shan-218 well, Shan-257 well, Yu-29 well, Yu-53 well, Yu-55 well).

\section{Conclusions}

We have then established the effect-oriented numerical simulation between porosity and different diagenesis parameters. The study can be summarized in the following main points:

(1) The process-oriented simulation of porosity was established for quartz sandstone and lithic quartz sandstone, respectively, from diagenetic evolution to the diagenesis stage B of middle diagenesis. Numerical simulation of effect-oriented is built from the macroporosity perspective and micropore-throat system perspective, based on diverse diagenetic parameters, such as grain size, quartz cement, kaolinite, hydromica, and calcite cement. The fitting results show that the main factors influencing the evolution of porosity and a pore-throat system are grain size and siliceous cement 
(2) The effect-oriented simulation between the porosity, the pore-throat median radius, and the main diagenetic factors was established in different grain size ranges $(0<0.5 \mathrm{~mm}, 0.5-0.75 \mathrm{~mm}, 0.75-1 \mathrm{~mm}$, and $>1 \mathrm{~mm})$. Under the comprehensive consideration that the effects of grain size and the contents of siliceous, kaolinite, hydromica, and calcite can have on the pore-throat evolution, the effect-oriented simulation can restore the porosity and the pore-throat radius of a reservoir elaborately. The fitting results were also proven to have a practical value for living examples

\section{Data Availability}

All data generated or analyzed during this study are included in this article.

\section{Conflicts of Interest}

The authors declare that they have no conflicts of interest.

\section{Acknowledgments}

This work was financially supported by the Scientific Research Program Funded by Shaanxi Provincial Education Department (Program No. 2017JS111), the Basic research program of Natural Science in Shaanxi Province (Program No. 2019JQ-151), and Innovation and entrepreneurship training program for college Funded by Shaanxi Provincial Education Department (Program No. S202010705113).

\section{References}

[1] L. F. Athy, "Density, porosity and compaction of sedimentary rock," AAPG Bulletin, vol. 14, no. 1, pp. 1-24, 1930.

[2] W. W. Rubey and M. K. Hubbert, "Role of fluid pressure in mechanics of overthrust faulting," AAPG Bulletin, vol. 70, pp. 167-206, 1959.

[3] D. C. Beard and P. K. Weyl, "Influence of texture on porosity and permeability of unconsolidated sand," AAPG Bulletin, vol. 57, no. 2, pp. 349-369, 1973.

[4] R. C. Selley, "Porosity gradients in North Sea oil-bearing sandstones," Journal of the Geological Society of London, vol. 135, no. 1, pp. 119-132, 1978.

[5] M. Scherer, "Parameters influencing porosity in sandstones: a model for sandstone porosity prediction: ERRATUM," AAPG Bulletin, vol. 71, no. 5, pp. 485-491, 1987.

[6] S. P. Dutton and L. S. Land, "Cementation and burial history of a low-permeability quartzarenite, Lower Cretaceous Travis Peak Formation, East Texas," Geological Society of America Bulletin, vol. 100, no. 8, pp. 1271-1282, 1988.

[7] P. A. Allen and J. R. Allen, Basin Analysis: Principles and Applications, Blackwell Publishing, Oxford, 1990.

[8] I. Van Keer, P. Muchez, and W. Viaene, "Clay mineralogical variations and evolutions in sandstone sequences near a coal seam and shales in the Westphalian of the Campine Basin (NE Belgium)," Clay Minerals, vol. 33, no. 1, pp. 159-169, 1998.
[9] S. Bloch, R. H. Lander, and L. Bonnell, "A nomalously high porosity and permeability in deeply buried sandstone reservoirs: origin and predictability," AAPG Bulletin, vol. 86, no. 2, pp. 301-328, 2002.

[10] D. B. He, F. X. Ying, J. M. Zheng, J. M. Zheng, H. L. Guo, and R. K. Zhu, "Numerical simulation of clastic diagenesis and its application," Petroleum Exploration and Development, vol. 31, no. 6, pp. 66-68, 2004.

[11] Z. Liu, X. J. Shao, B. Jin, H. Y. Li, X. M. Xu, and Q. S. Liang, "Co-effect of depth and burial time on the evolution of porosity for classic rocks during the stage of compaction," Geoscience, vol. 21, no. 1, pp. 125-132, 2007.

[12] S. N. Ehrenberg, P. H. Nadeau, and O. Steen, "Petroleum reservoir porosity versus depth: influence of geological age," AAPG Bulletin, vol. 93, no. 10, pp. 1281-1296, 2009.

[13] S. J. Huang, K. K. Huang, W. L. Feng, H. P. Tong, L. H. Liu, and X. H. Zhang, "Mass exchanges among feldspar, kaolinite and illite and their influences in secondary porosity formation in elastic diagenesis-a case study on Upper Paleozoic, Ordos Basin and Xujiahe Formation, Western chuan Depression," Geochemical, vol. 38, pp. 498-506, 2009.

[14] J. M. Ajdukiewicz and R. H. Lander, "Sandstone reservoir quality prediction: the state of the art," AAPG Bulletin, vol. 94, no. 8, pp. 1083-1091, 2010.

[15] D. F. Qu, Z. X. Jiang, H. M. Liu, and G. YJ, “A reconstruction method of porosity for clastic reservoirs during the crucial period of hydrocarbon accumulation," Acta Petrolei Sinica, vol. 33, no. 3, pp. 404-413, 2012.

[16] D. M. Indu and J. O. Peter, "Prediction of reservoir quality through chemical modeling," AAPG Memoir, vol. 19, pp. 1551, 1990.

[17] Y. S. Kang, J. S. Shen, and Z. H. Shen, Modern Mathematical Geology, Petroleum industry press, Beijing, 2005.

[18] R. C. Tobin, T. McClain, R. B. Lieber et al., "Reservoir quality modeling of tight-gas sands in Wamsutter field: integration of diagenesis, petroleum systems, and production data," $A A P G$ Bulletin, vol. 94, no. 8, pp. 1229-1266, 2010.

[19] M. A. Ahmadi, M. R. Ahmadi, S. M. Hosseini, and M. Ebadi, "Connectionist model predicts the porosity and permeability of petroleum reservoirs by means of petro-physical logs: application of artificial intelligence," Journal of Petroleum Science and Engineering, vol. 123, pp. 183-200, 2014.

[20] Z. K. Jin, L. Shi, W. Yan, X. E. Zhu, and B. Peng, "Contribution of sedimentary and diagenetic factors to clastic reservoir quality: quantitative determination by single factor comparison method," Journal of Palaeogeography, vol. 18, no. 4, pp. 535544, 2016.

[21] J. H. Fu, X. S. Wei, J. X. Nan, and X. H. Shi, "Characteristics and origin of reservoirs of gas fields in the Upper Paleozoic tight sandstone, Ordos Bain," Journal of Palaeogeography, vol. 15, no. 4, pp. 529-539, 2013.

[22] H. Yang, J. H. Fu, X. S. Liu, and P. L. Meng, “Accumulation conditions and exploration and development of tight gas in the Upper Paleozoic of the Ordos Basin," Petroleum Exploration and Development, vol. 39, no. 3, pp. 315-324, 2012.

[23] J. Z. Zhao, J. H. Fu, J. L. Yao et al., "Quasi-continuous accumulation model of large tight sandstone gas field in Ordos Basin," Acta Petrolei Sinica, vol. 33, Supplement 1, pp. 37-52, 2012.

[24] J. Z. Zhao, Q. Cao, Y. B. Bai et al., "Petroleum accumulation: from the continuous to discontinuous," Petroleum Research, vol. 2, no. 2, pp. 131-145, 2017. 
[25] Q. Cao, J. Z. Zhao, X. S. Liu, A. P. Hu, L. Y. Fan, and H. C. Wang, "Determination of physical property limits for the gas accumulation in tight sandstone reservoirs in the eastern Ordos Basin," Acta Petrolei Sinica, vol. 34, no. 6, pp. 10401048, 2013.

[26] X. S. Liu, L. F. Zhou, and Y. D. Hou, "Study of gas charging in the Upper Paleozoic of Ordos Basin using fluid inclusion," Acta Petrolei Sinica, vol. 28, no. 6, pp. 37-42, 2017.

[27] J. L. Luo, X. S. Liu, and X. Y. Fu, "Impact of petrologic components and their diagenetic evolution on tight sandstone reservoir quality and gas yield: a case study from $\mathrm{He} 8$ gas-bearing reservoir of Upper Paleozoic in northern Ordos Basin," Earth Science-Journal of China University of Geosciences, vol. 33, no. 5, pp. 537-545, 2014.

[28] Q. Cao, J. Z. Zhao, J. H. Fu et al., "Gas source conditions of quasi-continuous accumulation of the Upper Paleozoic in Ordos Basin,” Oil \& Gas Geology, vol. 34, no. 5, pp. 584-591, 2013.

[29] Q. Cao, J. M. Gao, L. Y. Fan, C. X. Pang, and J. Z. Yu, "Characteristics and significance of fluid inclusions in the Upper Paleozoic of southwest Ordos Basin," Natural Gas Geoscience, vol. 26, no. 12, pp. 2245-2253, 2015.

[30] K. Y. Hui, S. N. Zhang, D. M. Li, and J. N. Hu, "Reservoir petrology and diagenesis of lower Shihezi Formation and Shanxi Formation in northern Ordos basin," Journal of Chengdu University of Technology, vol. 29, no. 3, pp. 272278, 2002.

[31] X. Q. Ding, X. N. Zhang, W. Zhou, L. Z. Deng, and X. H. Li, "Characteristics and genesis of the Upper Paleozoic tight sandstone reservoir in the northern Ordos basin," Oil \& Gas Geology, vol. 28, no. 4, pp. 491-496, 2007.

[32] N. Ning, M. J. Chen, R. E. Liu et al., "Upper Paleozoic quartzsandstone reservoir diagenesis and pore evolvement, eastern Ordos basin," Natural Gas Geoscience, vol. 18, no. 3, pp. 334-338, 2007.

[33] D. W. Houseknecht and L. A. Hathon, "Hydrocarbons in an overmature basin. II. Is there a thermal maturity limit to methane production in Arkoma basin, Oklahoma and Arkansas," AAPG Bulletin, vol. 71, p. 8, 1987.

[34] N. Kutner, NETER. Applied Linear Regression Models, McGraw-Hill Education, New York, 2004.

[35] L.-h. Fu and W. Hui-wen, "A comparative research of polynomial regression modeling methods," Journal of Applied Statistics and Management, vol. 23, no. 1, pp. 48-52, 2004.

[36] S. M. Peng, Q. H. Xiong, C. J. Wang, Y. Cai, and Z. J. Wu, “A method of principal component analysis in comprehensive reservoir evaluation," Acta Petrolei Sinica, vol. 15, Supplement 1, pp. 187-194, 1994.

[37] R. Pan, X. M. Zhu, J. F. Zhang, and W. Li, "A model for comprehensive evaluation of reservoir quality based on principal component analysis: A case study of Bashijiqike formation in Kelasu tectonic zone," Petroleum Geology \& Experiment, vol. 36, no. 3, pp. 376-380, 2014. 